\title{
Recycled Asphalt Pavement Materials in Transport Pavement Infrastructure: Sustainability Analysis \& Metrics
}

\author{
Yunpeng Zhao*D, Dimitrios Goulias and Dominique Peterson
}

check for updates

Citation: Zhao, Y.; Goulias, D.;

Peterson, D. Recycled Asphalt

Pavement Materials in Transport

Pavement Infrastructure:

Sustainability Analysis \& Metrics.

Sustainability 2021, 13, 8071.

https://doi.org/10.3390/su13148071

Academic Editor: Antonio D'Andrea

Received: 25 May 2021

Accepted: 16 July 2021

Published: 20 July 2021

Publisher's Note: MDPI stays neutral with regard to jurisdictional claims in published maps and institutional affiliations.

Copyright: (c) 2021 by the authors. Licensee MDPI, Basel, Switzerland. This article is an open access article distributed under the terms and conditions of the Creative Commons Attribution (CC BY) license (https:// creativecommons.org/licenses/by/ $4.0 /)$.
Department of Civil and Environmental Engineering, University of Maryland, College Park, MD 20742, USA; dgoulias@umd.edu (D.G.); dfon95@umd.edu (D.P.)

* Correspondence: zyp1015@umd.edu

\begin{abstract}
Transportation infrastructure is one of the largest consumers of natural materials. To improve the environmental quality and sustainable development of transportation infrastructure, it is important to implement sustainable strategies in pavement construction and rehabilitation. The use of recycled materials is a key element in generating sustainable pavement designs to save natural resources, reduce energy, greenhouse gas emissions, and costs. The objective of this study was to propose a methodology for assessing the environmental and economic life-cycle benefits when using recycled asphalt pavement (RAP) materials in highway projects. Previous studies on life cycle analysis (LCA) using RAP focused on the economics and/or environmental impacts during the material production process. Thus, there is a need to consider sustainability analysis at all stages of construction and rehabilitation during the performance period of pavement structures. This study addresses this need with the proposed methodology. The suggested approach could be potentially implemented in a pavement management system (PMS) so as to introduce sustainability principles in optimizing alternative rehabilitation strategies. The methodology includes various steps for the analysis, starting with condition assessment of the existing highway, identifying alternative structural pavement designs, predicting service life, setting up alternative rehabilitation strategies, and conducting life cycle environmental and economic analysis. To demonstrate the value of the methodology, a comparative parametric study was conducted on two real case study projects representing actual field conditions for primary roads in Maryland. These case studies were used in order to quantify the economic savings and environmental benefits of using different levels of RAP in highway rehabilitation. The results of the analysis indicate that incorporating RAP in pavement rehabilitation can contribute substantially to cost savings and environmental impact reduction (e.g., greenhouse gas emission, energy, water, and hazardous waste). The benefits illustrated in this study are expected to encourage wide adoption of the proposed methodology and the use of recycled materials in highway construction and rehabilitation. The methodology is transferable where similar materials and highway construction techniques are used.
\end{abstract}

Keywords: infrastructure sustainability; recycled materials; pavements; life cycle analysis; environmental impacts; sustainability metrics

\section{Introduction}

The United States' national highway system requires new construction and extensive rehabilitation of highways to meet the growing traffic demand and guarantee the safety of drivers [1]. The maintenance and rehabilitation of this extensive highway network system consume large amounts of natural resources and energy, produce large quantities of waste and generate significant amounts of greenhouse gas emissions [2]. Thus, state Departments of Transportation (DOTs) have been aiming to adopt an ever-increasing amount of recycled materials in pavement construction and rehabilitation. The benefits that can be achieved by using large amounts of recycled materials include reducing the use 
of natural resources; eliminating waste materials generated for disposal; reducing energy and water consumption; and reducing greenhouse gas emissions [3].

Recycled asphalt pavement (RAP) is the most common recycled material used in hot mixed asphalt (HMA) and to some degree as aggregate in base layers. The engineering properties of using RAP in highway construction applications have been explored by several studies [4]. However, its contributions to sustainability, in terms of greenhouse gas emissions reduction (GHG), energy and water demand reduction, and economic benefits using life-cycle cost analysis (LCCA), have been examined to a lesser degree. Furthermore, the potential widespread use and the sustainability benefits of RAP and other recycled materials need to be considered within the pavement management system (PMS) analysis when identifying the best rehabilitation strategy for each project. Chesner et al. [4] described RAP and its potential applications in highway construction. The significant economic savings when RAP is used have been reported by some state agencies [5]. During roadway rehabilitation, the existing asphalt concrete is removed by milling the surface and pulverizing the old HMA. The material obtained from this process is referred to as RAP. Ventura et al. [6], and more recently, AL-Qadi et al., [7], Aurangzeb et al. [8], and Del Ponte et al., [9] discussed the potential environmental and economic benefits and trade-offs of using RAP in pavements. However, only a limited percentage of RAP was included in these analyses. Furthermore, none of the studies provided a systematically quantitative determination of the economic savings and environmental benefits when substituting conventional (i.e., virgin) materials with RAP [10]. Thus, a more comprehensive analysis of life cycle economic benefits and environmental impact analysis is needed [11]. Furthermore, previous studies on the LCA analysis using RAP materials focused on the economics and/or environmental impacts during the material production process, AL-Qadi et al., [7], Aurangzeb et al. [8], and Del Ponte et al., [9]. Thus, there is a need to consider all stages in the roadway life-cycle performance phases (i.e., construction, maintenance, rehabilitation) in order to address all potential impacts and benefits of using RAP in the LCA analysis of roadway projects. This study addresses this need with the proposed holistic approach methodology that quantifies the LCA environmental benefits and economic savings throughout the entire performance period of alternative sustainable strategies by considering both construction and rehabilitation stages. To demonstrate the value of the methodology, the comparative parametric study was conducted on two real case study projects representing field conditions for primary roads in Maryland, and typical pavement construction practices in the northeast region of the US.

The proposed methodology for systematically generating and assessing sustainable pavement rehabilitation strategies includes various steps: condition assessment of the existing roadway; creating conventional (i.e., with new raw materials) and alternative sustainable (i.e., with recycled materials) strategies; pavement structural design analysis and service life predictions; conducting life cycle environmental and economic analysis, and comparing alternatives; and, criteria for selecting the best and more sustainable strategy using the analysis and sustainability metrics. While the proposed approach is briefly described in the methodology section, this paper primarily focuses on the sustainability analysis. For showing the value of the proposed methodology, comparative life cycle analysis (LCA) was conducted to quantify the economic savings and environmental benefits associated with the substitution of different levels of RAP with conventional virgin materials in highway projects. The analysis was conducted using the pavement life-cycle assessment tool for environmental and economic effects (PaLATE, version 2.0, 2021). This tool considers the environmental and economic effects throughout the entire supply chain including materials production, construction, and rehabilitation phases. For example, inputs pertinent to the materials used during initial construction may include both economic and environmental considerations in regards to methods and equipment used during production as well as transportation of these materials to the construction site. 


\section{Methodology}

The steps of the proposed methodology for generating and analyzing alternative sustainable rehabilitation strategies are presented in Figure 1 and briefly described next. Since the various highway agencies use different condition assessment techniques, threshold criteria for acceptable levels of condition, performance prediction models, pavement design methods, maintenance and rehabilitation techniques, and LCA tools, it was the objective of this study to define the overall methodological framework for generating and analyzing sustainable pavement rehabilitation strategies, Figure 1, so that can be adopted and adapted by each agency based on their local practices.

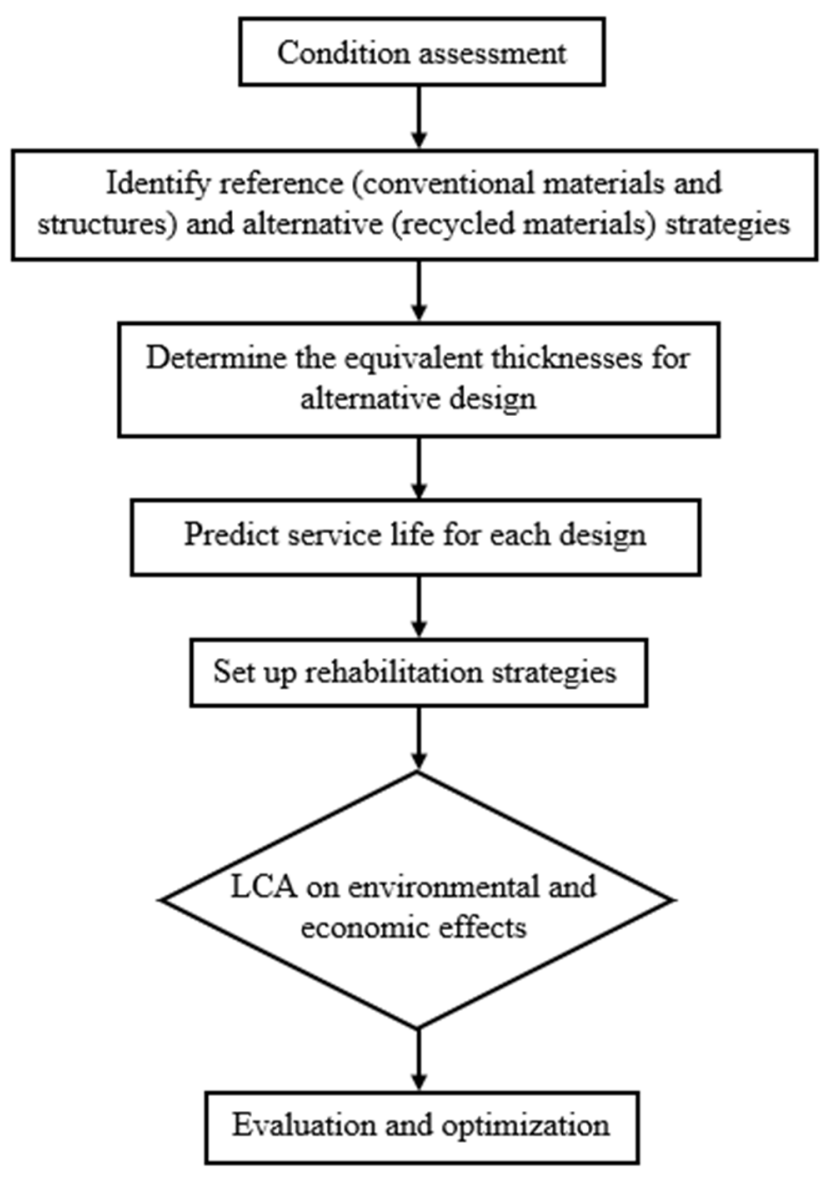

Figure 1. A methodological framework for sustainable pavement rehabilitation strategies.

\subsection{Pavement Condition Assessment}

The first step of the methodology is to assess the pavement condition of the existing road. The present condition is particularly important since it evaluates the current quality of materials and pavement structure. This will identify what level of the existing materials can be recycled, the method of recycling, (i.e., in-situ recycling versus plant recycling), and any structural aspects that need to be addressed. Distress surveys are the most common condition assessment methods used by DOTs. Such surveys identify distresses, severity levels, and density of such defects on the pavement surface through a visual examination of either a representative portion or the entire roadway project. The surface distress data are then used to calculate the condition indexes. The most popular one is the pavement condition index (PCI) which provides an overall rating of the condition of the pavement, Table 1. PCI provides a numerical value ranging from 0 to 100, with 100 representing the perfect condition and 0 representing the failed condition [12]. Over the years other methods of assessing pavement conditions have been developed based on roughness, friction, surface deflections. Furthermore, recent developments in fast and accurate non- 
destructive methods for field conditions, such as ground penetration radar (GPR), can be used for assessing such conditions $[13,14]$.

Table 1. Pavement condition index.

\begin{tabular}{cc}
\hline Pavement Condition & PCI Scale \\
\hline Good & $85-100$ \\
\hline Satisfactory & $70-85$ \\
\hline Fair & $55-70$ \\
\hline Poor & $40-55$ \\
\hline Very Poor & $25-40$ \\
\hline Serious & $10-25$ \\
\hline Failed & $0-10$ \\
\hline
\end{tabular}

Note: adaptation after ASTM D6433 [12].

\subsection{Identify Conventional and Alternative Strategies}

The next step involves identifying potential rehabilitation strategies. This includes identifying the conventional one where 100\% new raw materials are used, and the sustainable alternatives using recycled materials in the surface and base layers. Many recycled materials or industrial by-products can be employed in pavement construction, such as $\mathrm{RAP}$, recycled concrete materials (RCM), construction and demolition waste (CDW), fly ash, glass, crumb rubber, and foundry sand. Among these, RAP is the most common recycled material used in pavement structures since it can be used in both the surface and base layers [7]. Figure 2 shows a schematic of the RAP production process. Studies have shown that RAP can be processed to achieve equal or better engineering performance than conventional materials [15]. The interest in using RAP was particularly emphasized during the 1970s oil crisis and the increasing cost of asphalt binders ever since [16]. The use of RAP has become a relatively common practice in most countries. Thus, RAP was adopted in the case studies for generating alternative strategies. Several studies in Europe and the United States have concluded that even recycling levels of $80 \%$ RAP in asphalt mixtures are feasible solutions depending on the quality of the reprocessed material [17]. However, current regulations in the United States restrict the use of these materials to $50 \%$ levels [18]. Such constraint was also considered in this study when generating the alternative rehabilitation strategies to examine.

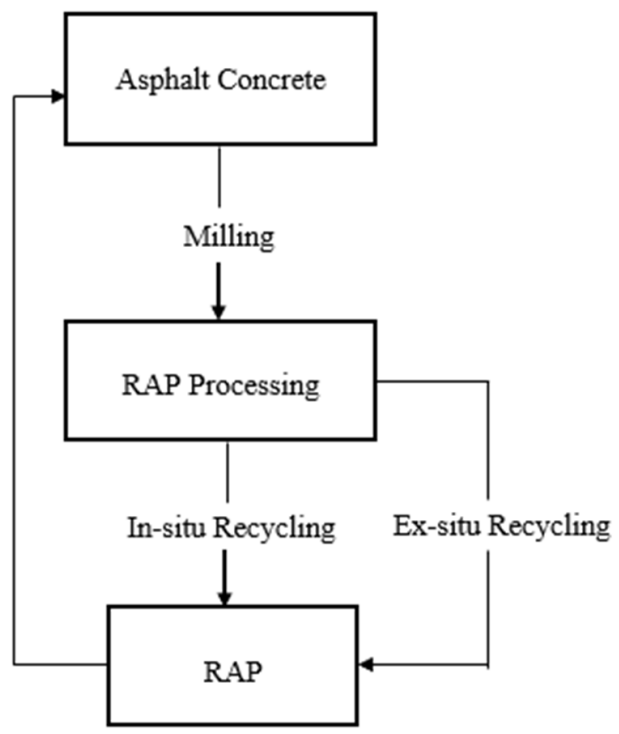

Figure 2. Production process of RAP. 


\subsection{Determine Equivalent Thicknesses for Alternative Designs}

For the same traffic level and environmental conditions, pavement structural thicknesses will vary in function of the materials used. Thus, it is necessary to determine the pavement layer thicknesses. The layer thicknesses for the conventional and rehabilitation strategies can be determined using the AASHTO pavement design guide [19]. Alternatively, the mechanistic-empirical pavement design guide (MEPDG) can be used as well [20]. The AASHTO equation was used in this study to determine the equivalent thickness for the alternative designs.

\subsection{Predict Pavement Service Life}

Depending on the initial design quality (i.e., materials and layer characteristics, design traffic level, and environmental parameters), the useful service life of each pavement structure can be estimated. To identify the useful service life of a pavement structure the minimum acceptable condition (i.e., when the next rehabilitation is required) should be defined. The present serviceability index (PSI) is used in the AASHTO pavement design guide [19]. The majority of the states use a PSI value of 2.5 as the selected threshold [21]. Other condition indexes have been related to PSI including the International Roughness Index, IRI, (an index based on roughness measurements on the roadway surface), as well as PCI [22,23]. In terms of pavement design, as well as for predicting the remaining service life, the MEPDG can be used which identifies pavement conditions in terms of IRI, with a threshold value for rehabilitation equal to an IRI of $2.7 \mathrm{~m} / \mathrm{km}$ [20]. Similarly, to the AASHTO design method, MEPDG considers three major categories of input variables in the analyses including, material properties, traffic load data, and climatic parameters [20].

\subsection{Identifying Rehabilitation Strategies}

Based on the current pavement condition (i.e., PCI) reflecting the quality of the existing pavement materials and structure, the remaining service life can be estimated, and appropriate recycling techniques can be selected for pavement rehabilitation. An example is shown in Table 2 after a major national study addressing such relationships [3]. For example, hot-in place recycling (HIR) is usually used when the pavement distresses are minimal and located on the surface layer. In this case, $\mathrm{PCI}$ is between satisfactory to good levels (i.e., between 70 to 100), reflecting thus a good quality RAP and the remaining paving materials, and there is no evidence of structural problems. Cold-in place recycling (CIR) is used when the distresses are more severe and extend beyond the surface layer. In this case, PCI has a fair level (i.e., between 55 to 70 ) reflecting recycled materials that require significant improvement in terms of mechanical properties. Finally, full-depth reclamation (FDR) is used to reconstruct layers and to increase structural capacity. In this case, a lower $\mathrm{PCI}$ corresponds to values below 55, indicating that the existing recycled materials require extensive improvement throughout the pavement layers [3]. As expected, in-situ recycling of the existing pavement reduces the need for transportation of material to and from the construction site and/or disposal to the landfill. This will help avoid, or reduce, the disposal of construction materials, and thus reduce the consumption of energy, natural resources, emissions, and eventually costs. Hot in-place recycling is the most common method used in the construction of highways since the existing in-situ pavement material has not undergone extensive deterioration and fracture compromising future performance. In this technique, new materials and RAP are mixed at different proportions until the required properties and quality are achieved. Furthermore, implementing sustainability principles in this stage of identifying alternative strategies will aid in reducing energy consumption, carbon footprint, and greenhouse gas emissions. In this study HIR was used since the existing pavement conditions of the field case studies were considered to be at satisfactory to good levels, Table 2. 
Table 2. Selection of recycling techniques for pavement rehabilitation.

\begin{tabular}{cc}
\hline Pavement Condition & Recycling Method \\
\hline Satisfactory to Good & HIR \\
\hline Fair & CIR \\
\hline Poor or Lower & FDR \\
\hline Note: Adaptation after NCHRP Synthesis 421 [3].
\end{tabular}

\subsection{Life Cycle Assessment}

Once the rehabilitation strategies are identified, life cycle economic and environmental impact analysis can be performed for both conventional and alternative sustainable designs. Currently, there are several tools available for performing LCA, some of which are specifically developed for pavement structures [1,11]. It is important to select analysis tools that address both economic and environmental assessment. Since LCA is conducted over a certain period, the tool should be flexible enough to consider current and future investments in time by considering net present value (NPV) or uniform annual cost [24]. Similarly, the LCA tool in regards to environmental impacts should consider the implications from both current and future maintenance and rehabilitation interventions on the pavement structure during the entire performance period. While in this study PaLATE was used as an example LCA tool [11], other tools can also be considered for such analysis. This tool considers the analysis inputs such as materials, layer thicknesses, densities, unit costs of production, transportation, and placement in relation to equipment used, pertinent energy and water consumption, as well as emissions. Such analyses are conducted for each stage of materials production, transportation, and construction. It also considers initial construction as well future maintenance and rehabilitation operations throughout the entire service life. A variety of data and default values are available in the PaLATE database pertinent to a wide set of recycled materials. These include parameters required to calculate both economic and environmental impacts for a project. The material, construction, maintenance, landfill, and other input parameters for this study were based on local Maryland and regional values from the northeast US region. These input parameters can be easily modified to reflect the specific region of the construction projects (i.e., costs, materials and densities, construction methods and equipment used, and so on). PaLATE employs an input-output (EIO) LCA function which permits the assessment of the economic and environmental impacts associated with recycled and conventional materials.

The alternative rehabilitation strategies can be thus compared based on the LCA economic and environmental results, in terms of the individual values obtained for LCA cost, energy, water, emissions, and so on. Nevertheless, it is often important and desirable to consider an overall assessment for each sustainability strategy, in relation to the remaining, by comparing them or ranking them with an overall rating index. For this reason, a sustainability rating system can be used which identifies an overall rank or score. Such sustainability score can be then used to compare the alternative strategies between them, and with the conventional strategy where raw construction materials are used. In this study, the $\mathrm{BE}^{2}$ ST-in-Highways sustainability rating tool was used [25]. Thus, the economic and environmental impact results obtained from PaLATE for each alternative strategy were used in $\mathrm{BE}^{2} \mathrm{ST}$-in-Highways for rating each alternative. This rating system awards sustainability points to key parameters, (such as life cycle cost reduction, energy consumption, and hazardous waste reduction, amount of in-situ and ex-situ recycling, and so on), in relation to predefined reduction target levels for each one of these. While the details of such a rating system are described later with the case studies, it is worth mentioning that any sustainability rating system can be used that reflects local conditions and practices in the region of interest [26]. $\mathrm{BE}^{2} \mathrm{ST}$-in-Highways is flexible enough to modify key sustainability parameters; corresponding target reduction values and reward points; and relative weights between these parameters, (i.e., reflecting their relative importance, for example, the cost versus energy, energy versus water reduction, and so on). Such parameters provide a 
numerical score reflecting the overall sustainability ranking (i.e., number of reward points leading to a total sustainability score, and thus ratings such as gold, silver, etc.). The analysis and sustainability score can be then used to select the best possible sustainable rehabilitation strategy for a specific project. It is worth mentioning that such analysis and ranking could be easily integrated into a PMS for optimizing the allocation of investments (maintenance and rehabilitation) in a highway network in conjunction with sustainability requirements and recycling target levels.

\section{Case Studies}

As emphasized earlier, this paper focuses on the sustainability analyses for showing the value of the proposed approach in comparing alternative strategies in regards to life cycle economic and environmental impact. Such analyses were conducted for the construction of two different roadways. The alternative rehabilitation solutions considered a conventional design using new construction materials and sustainable alternative designs considering recycled materials. The analyses were conducted using PaLATE [11]. The required inputs for the analysis of each strategy include among other project characteristics, analysis period, planned maintenance and reconstruction schedule, and present worth value. An example of input parameters is shown in Table 3. For both construction projects under consideration, the analysis was conducted for a road width of $7.3 \mathrm{~m}$ (i.e., two travel lanes), $1.6 \mathrm{~km}$ in length (i.e., one-mile stretch). The LCA sustainability analysis was conducted over an analysis period of 40 years with a scheduled $50 \mathrm{~mm}$ overlay every ten years and reconstruction every 20 years. The time intervals were determined based on the estimated traffic level and deterioration rates using the rehabilitation design guide principles of the AASHTO design guide [19]. Several studies indicated that the use of RAP in HMA can match or enhance mixture properties and performance in relation to conventional materials when appropriate rejuvenators and gradation adjustments are used [3-5]. Similarly, the use of RAP in the base or subbase can meet or slightly exceed the mechanical properties and performance in relation to the granular aggregate base, GAB, [1,2,27]. Thus, in this analysis, the same performance was assumed for surface and base/subbase materials incorporating RAP in relation to conventional materials.

Table 3. Input parameters for field case studies on primary roads.

\begin{tabular}{cc}
\hline Parameter & Value \\
\hline Road Width & $7.3 \mathrm{~m}$ \\
Road Length & $1.6 \mathrm{~km}$ \\
Wearing Course Depth & $10.16 \mathrm{~cm}$ \\
Graded Aggregate Base & $20.32 \mathrm{~cm}$ \\
Analysis Period & 40 years \\
Overlay (50 mm) & @ year $10 \& 30$ \\
Reconstruction & @ year 20 \& 40 \\
\hline
\end{tabular}

The first step in the analysis is to calculate volumes and weights in the function of the identified pavement design for each alternative strategy. For this study densities of hot mix asphalt (HMA), asphalt treated base (ATB), and graded aggregate base (GAB) was adjusted to represent the materials used in the region of the construction projects. Distances between construction site, production plant, and quarry, and landfill are also considered for accounting into the analysis of all economic and environmental-related parameters during material production and processing, transportation, and placement. The environmental analysis includes among other, greenhouse gas emissions, energy use, water consumption, waste generation, particulate matter, and human toxicity potentials. It is anticipated that when recycled materials are used saving in $\mathrm{CO}_{2}$ emissions may be observed.

Two types of roadways were included in this study, with two and three pavement layers. These represent typical roadways in the region with moderate and heavy traffic respectively. The pavement structural parameters are shown in Figure 3. The first roadway 
consists of a two-layer pavement design structure with an HMA surface layer and a GAB base, while the second one has an intermediate layer of ATB to account for the heavier traffic. The current condition of the two roadways was considered as satisfactory (i.e., PCI $70-85$ ) such that a relatively high percentage of RAP (i.e., 50\%) is allowed to be used in HMA for rehabilitation.
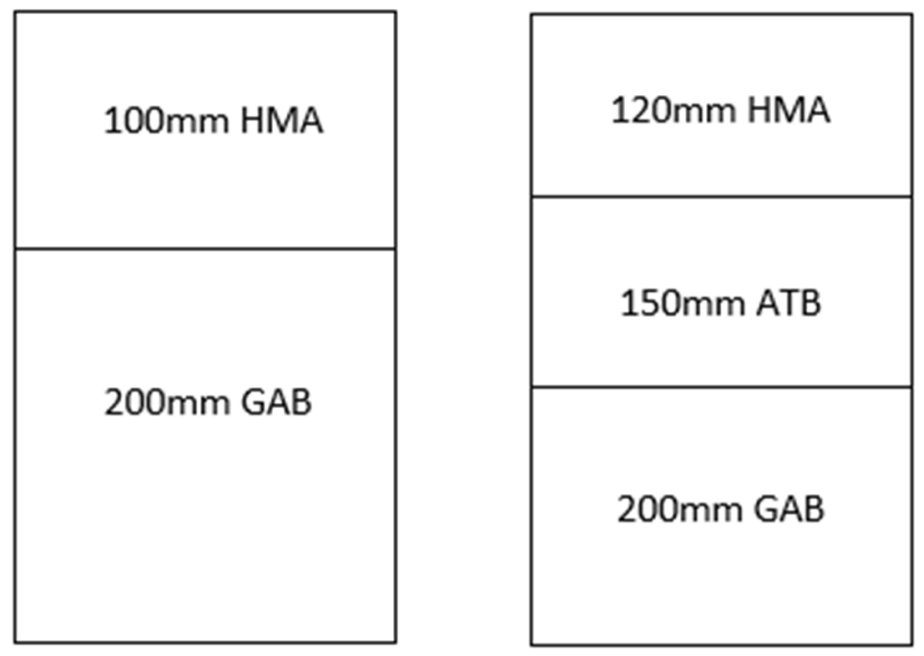

Figure 3. Schematic roadway pavement designs for real case studies.

For each case study, a set of alternative sustainable strategies were considered based on the current PCI condition rating of the pavement structure. The objective of the alternative strategies was to evaluate the economic and environmental benefits by substituting the surface layer (HMA), intermediate layer (ATB), and the base layer (GAB) with RAP at various percentages. Figure 4 provides the RAP percentages used in each layer for the two-layer pavement case. The RAP percentage in the HMA layer varied from $10 \%$ to $50 \%$ while for the GAB layer a RAP content ranging from $25 \%$ to $45 \%$. The reference case represents the conventional alternative where new virgin materials were used for both layers.

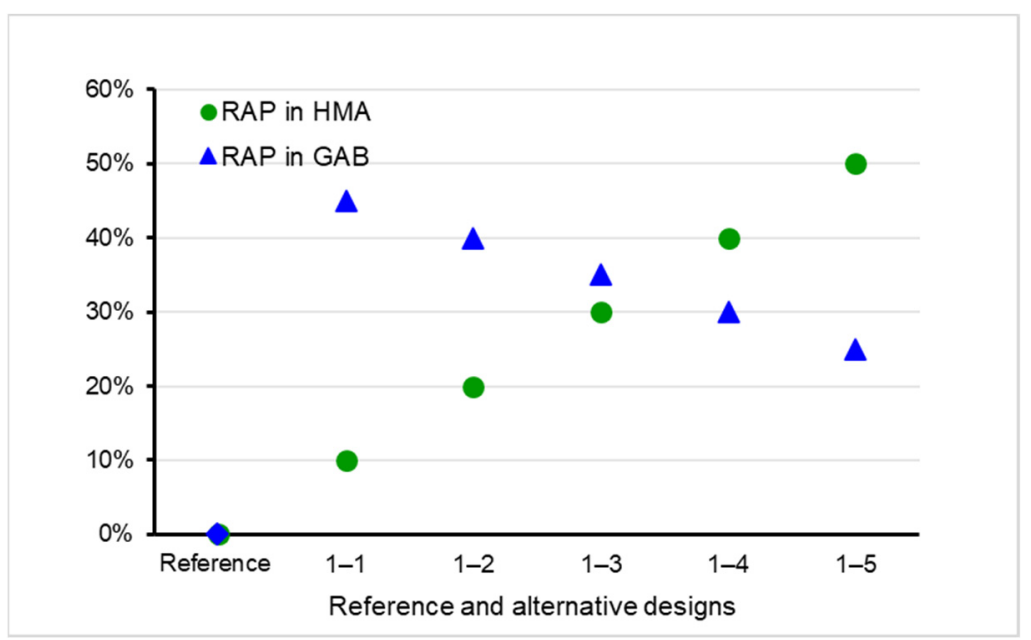

Figure 4. Alternative strategies for the two-layer pavement case.

Figure 5 provides the alternative sustainable rehabilitation strategies for the three-layer roadway case. As in the previous case, the alternative strategies were generated by varying the percentage of RAP in the HMA, ATB, and GAB layers. A survey conducted by Federal Highway Administration's RAP expert task group indicated that the most common RAP content in the hot mix used in the United States is around 20\%, even though specifications 
of some states allow up to 50\% [21]. Thus, $20 \%$ and 50\% of RAP in HMA were selected to reflect the currently common practice and maximum levels identified by many states. Past studies also examined the feasibility of using $100 \%$ RAP as a new pavement course, and thus, the percentage of RAP in GAB and ATB ranges 0-100 in the case studies [27] Specifically, the RAP in HMA ranged from 0 to $50 \%$, in ATB from 0 to $100 \%$, and in GAB from 0 to $100 \%$.

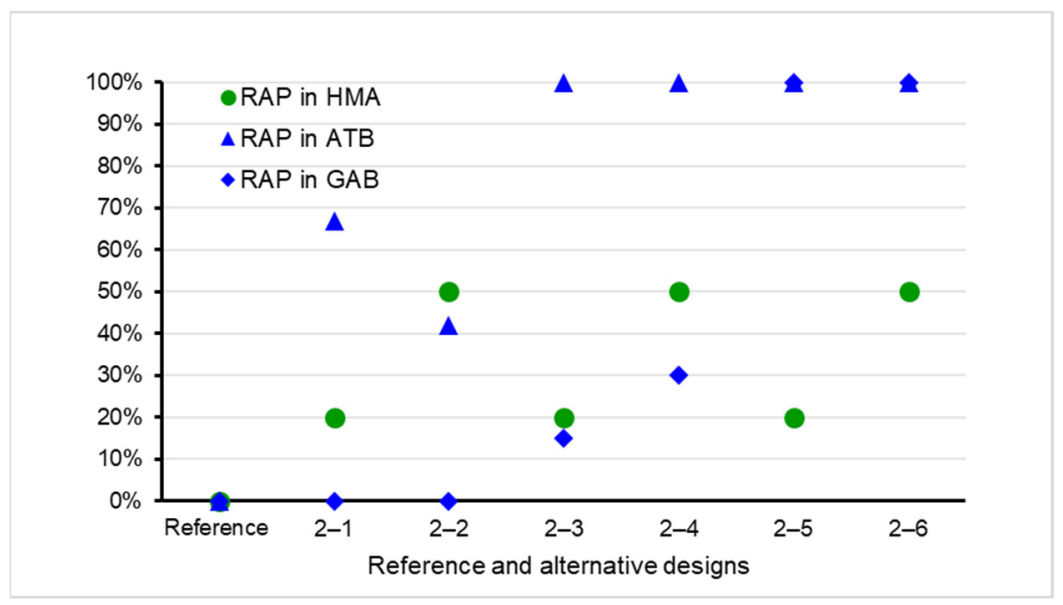

Figure 5. Alternative strategies for the three-layer pavement case.

\section{Results and Analysis}

\subsection{Economic Implications}

The results of the LCCA are presented in Figures 6 and 7. A discount rate of $4 \%$ was considered in the calculation of NPV values for each alternate for accounting costs pertinent to future maintenance and rehabilitation actions. As can be observed from the analysis of the two-layer pavement system, a life cycle cost reduction is observed with the increase in recycling material in HMA (e.g., RAP in the surface layer) and GAB base layer. Specifically, a $21 \%$ reduction in cost was observed when $10 \%$ HMA and $45 \%$ GAB were substituted with RAP. The cost reduction continues to increase as more RAP was used in the HMA layer. A total reduction of $26 \%$ in the life cycle cost was observed when $50 \%$ RAP was used in HMA, and 25\% RAP in GAB. Since the cost of HMA materials is higher than that for the base layer, using more RAP in the surface layer leads to higher cost savings. Nevertheless, at a certain level of RAP in HMA and GAB cost reductions tend to vary to a lower degree, (i.e., strategies 1-3 to 1-5).

The LCCA for the three-layer roadway, Figure 7, indicated that the alternative sustainable strategies provided a lower life cycle cost than the conventional case of using new raw construction materials. The higher cost saving was observed to be equal to $32 \%$ when $100 \%$ RAP was used in the intermediate and base layers and 50\% RAP in the HMA layer (e.g., alternative 2-6).

In all cases, the alternative sustainable strategies produced a lower life cycle than the reference conventional strategy (i.e., using new materials), indicating that the use of recycled materials on pavement construction provides significant economic savings. Cost savings did vary in relation to the type and percent of recycled material used, with a greater percentage leading to lower construction costs. The savings of the alternative strategies are attributed either to the reduction in material production cost and/or transportation cost. The life cycle cost broken down by materials, transportation, processes (i.e., equipment), labor, and profit (i.e., overhead) were also analyzed. By processing and using RAP on site, the transportation cost for virgin materials delivered to the construction site, and, the waste materials sent to the landfill for disposal (or to the plant for follow-up reuse to another project or application) can be reduced or minimized producing thus significant reduction to the total rehabilitation cost. The reduced use of virgin aggregate replaced 
by RAP produces another significant reduction in project cost. Although the cost for the hot in-place recycling (HIPR) process increased with an increasing amount of RAP, this had minimal impact on total rehabilitation cost in relation to the overall materials and transportation costs.

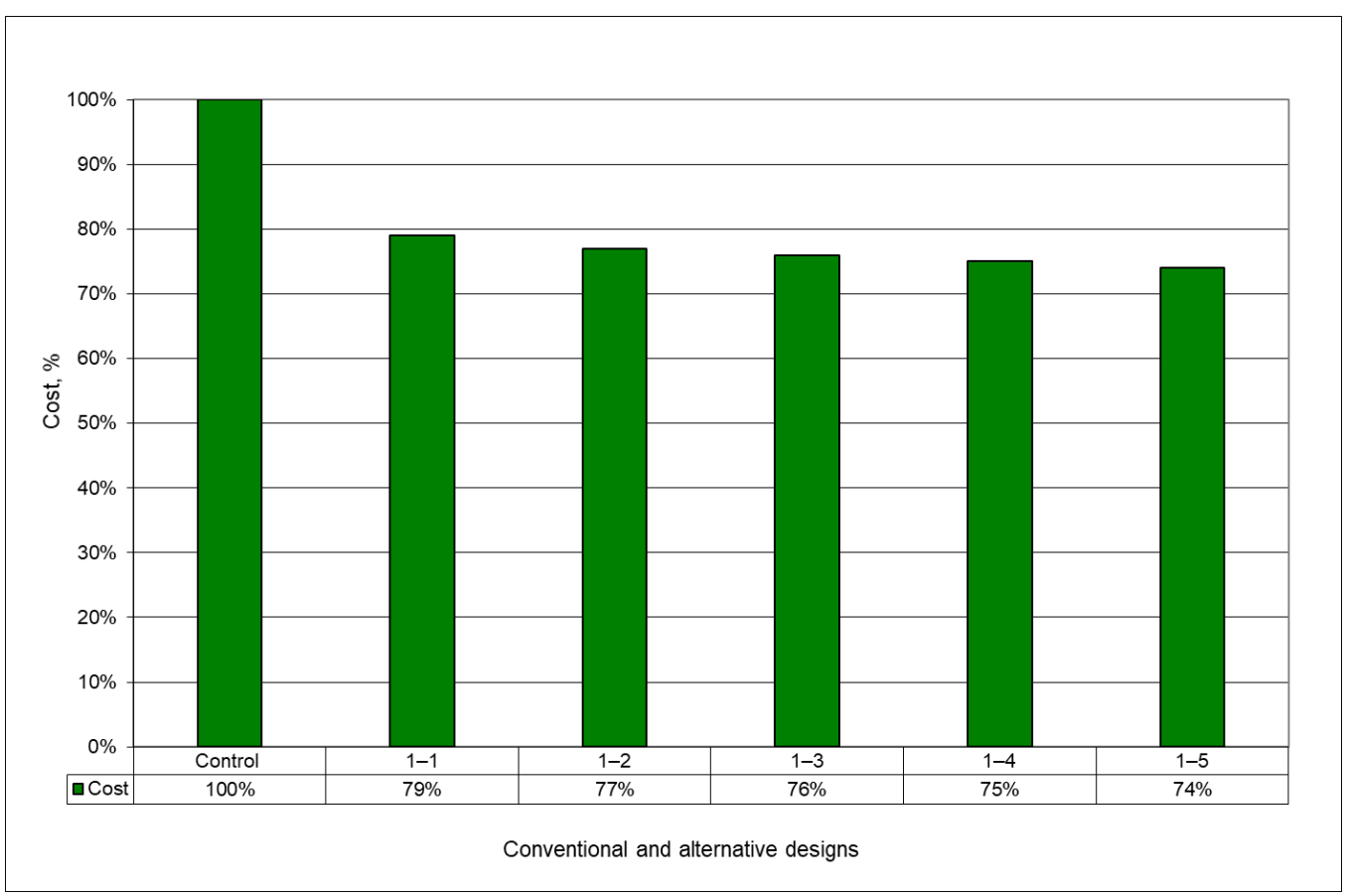

Figure 6. LCC comparison of conventional and alternative rehabilitation strategies (two-layer system).

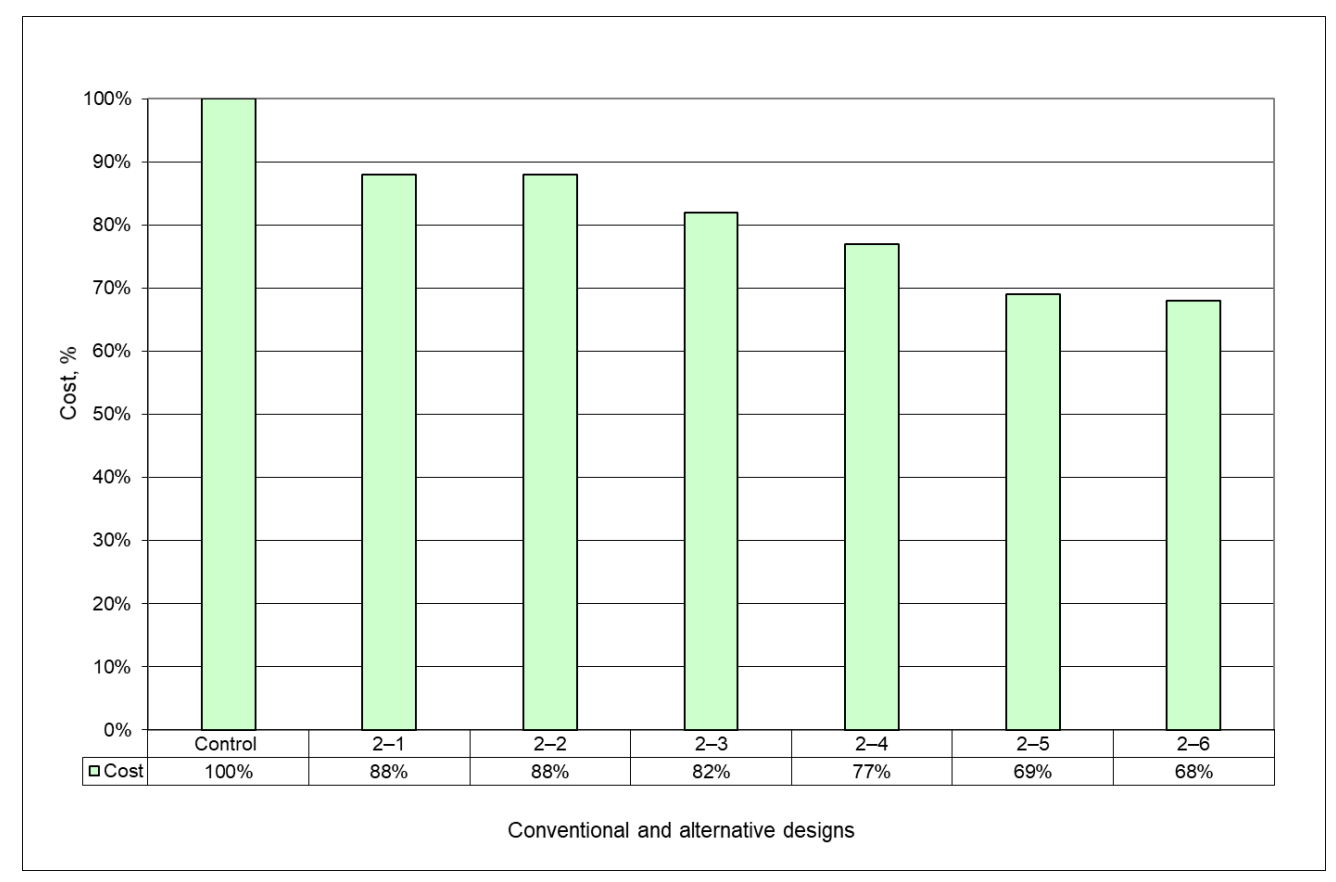

Figure 7. LCC comparison of conventional and alternative rehabilitation strategies (three-layer system). 


\subsection{Environmental Impact}

The environmental impact in PaLATE considers the impact of materials production and processing, construction equipment performance, and transportation both during initial construction and maintenance activities. The results obtained through life cycle environmental analysis are energy consumption, pollution emissions, water consumption, as well as hazardous waste generation. The environmental impacts of both conventional design and sustainable alternatives for the two-layer roadway are presented in Figure 8, while Figure 9 presents the results for the three-layer roadway. Some of the most relevant results are discussed next.

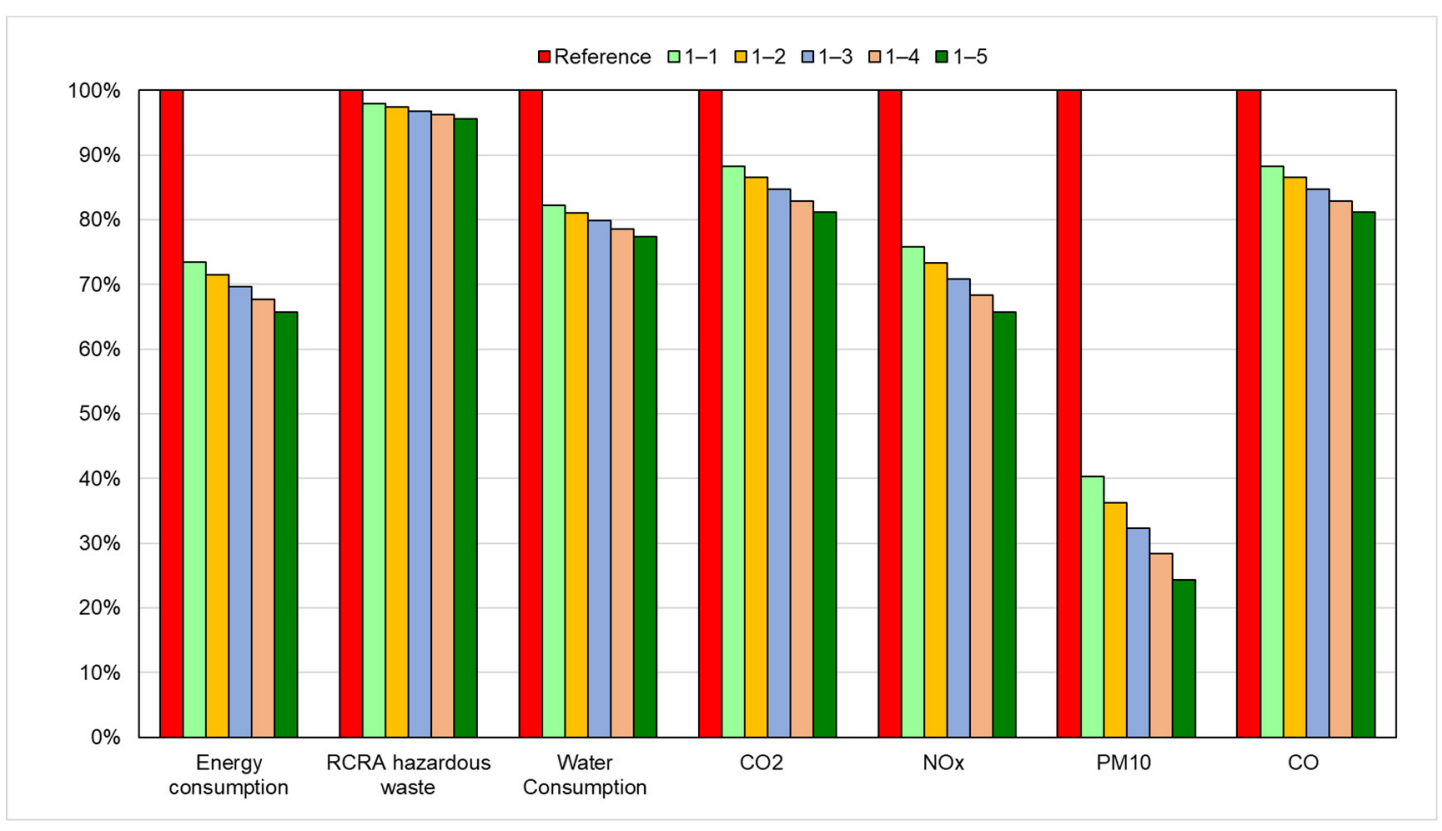

Figure 8. Life-cycle environment impact of alternative rehabilitation strategies (two-layer system).

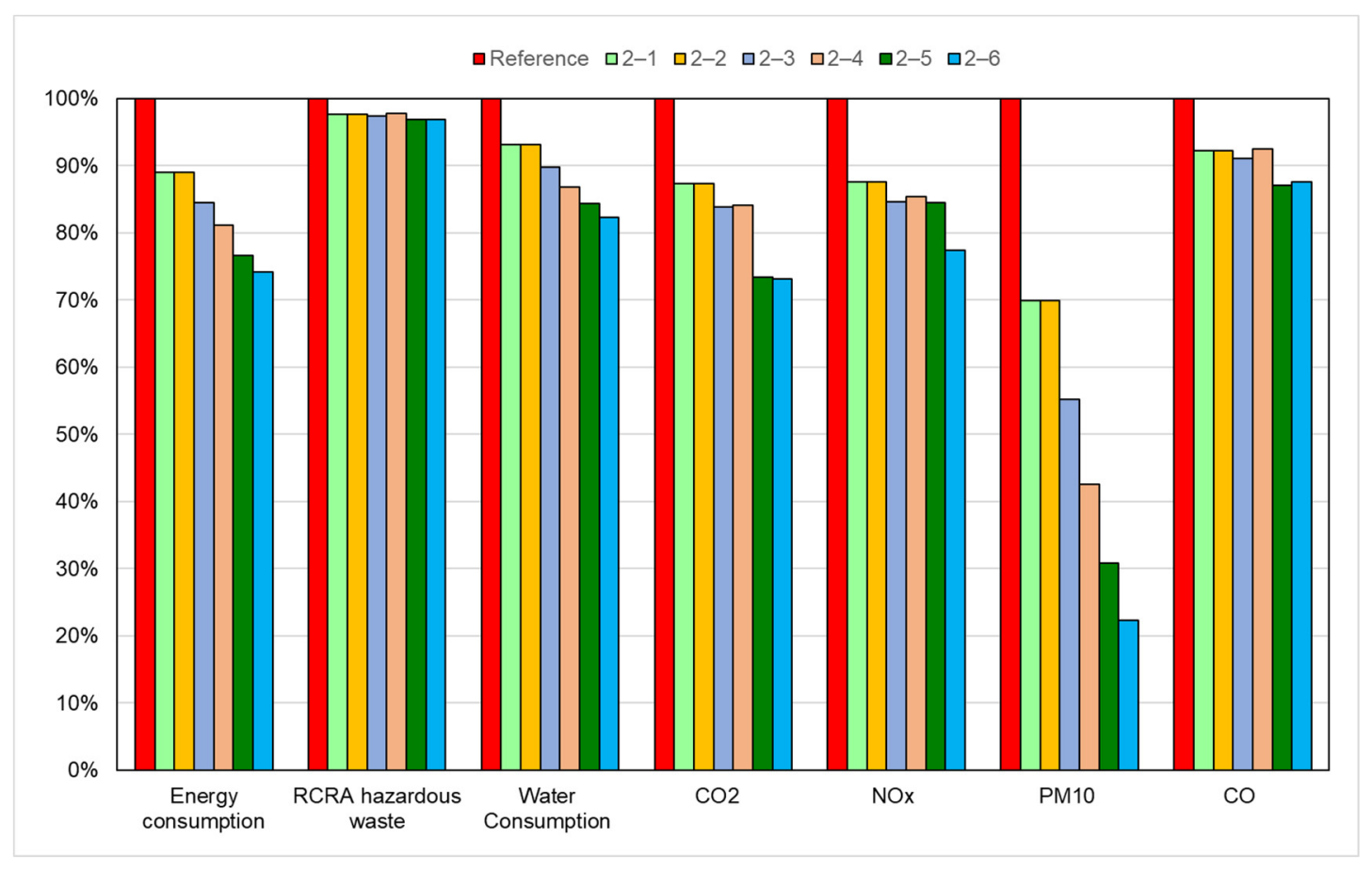

Figure 9. Life-cycle environment impact of alternative rehabilitation strategies (three-layer system). 
Increasing the use of RAP resulted in a reduction in energy use for all alternative strategies, and with maximum reductions of $36 \%$ observed for alternative $1-5$ and $26 \%$ for alternative strategy $2-5$. Therefore, energy consumption can be reduced significantly by increasing the percentage of RAP in HMA. It is also observed that a large amount of water savings (23\%) and greenhouse gas emissions reduction $(19 \%)$ were observed for the proposed strategy (1-5) compared to the reference case. The energy reduction reflects the lower demand in transportation due to the on-site recycling of materials, lower need to transport new materials to the construction site, and decreased amount of waste materials disposed to the landfill. A significant reduction (equivalent to 75\%) was observed for PM10 emissions (e.g., particulate matter of 10 micrometers and smaller, representing ambient air quality particle pollution as defined by the Environmental Protection Agency, EPA). The lower PM10 emissions are attributed to the decreased need for loading and hauling operations associated with the lower amounts of virgin and/or landfilled materials. RAP in HMA has a significant influence on $\mathrm{CO} 2$ emissions reduction. This is associated with the fact that RAP has already a certain amount of asphalt binder, reducing thus to some degree the need for a total new binder needed to be added to the mixture. As it is well-known binder production is a process associated with significant levels of energy and emissions.

\subsection{Sustainability Rating}

As mentioned earlier an overall assessment of each alternative strategy in regards to sustainability is often desired. In this study, BE ${ }^{2}$ ST-in-Highways was used. This sustainability metrics tool considers nine factors for assessing each alternative strategy in relation to a reference strategy. The reference strategy to compare all sustainable alternatives against to be the conventional one where all new virgin raw materials were used. Figure 10 presents the nine factors considered in the rating and includes energy use, global warming potential, GWP, in-situ \& ex-city recycling, water consumption, life cycle, and social carbon costs, traffic noise, and hazardous waste. The relative weight of each factor can range from 0-100 to reflect their relative importance concerning local conditions and policies pertinent to the construction projects. For example, in some regions water conservation or energy reduction may be more critical than cost savings, and so on. Thus, higher weights may be associated with such critical parameters. For this study, the relative weights assigned to these parameters were based on past recommendations and studies for the study region [10] and are as follows: energy, global warming, in-situ recycling, water consumption, LCC, and hazardous waste at $15 \%$; and SCC with a relative weight of $10 \%$. The total percentage of the relative weights adds up to $100 \%$. It is important to mention what social carbon costs are associated with the cost of reducing global warming. Such a parameter is often used by highway agencies to enforce sustainable construction, and it is based on USD/Mg of $\mathrm{CO}_{2}$ emissions [25]. This sustainability metric tool assigns rewards points in relation to the ability of each strategy to reduce cost and environmental impact at specific levels as related to these parameters. While the details of such interworks are described elsewhere [25], an example of such scoring is provided in Table 4 with alternative strategy 1-5. In this case, the energy reduction in relation to the conventional strategy employing new materials was of the order of $20 \%$ rewarded with a score of two points. Similar scores were obtained for GWP, in-situ recycling, water consumption, and LCC. Lower scores were obtained for social carbon cost, traffic noise reduction, and hazardous waste reduction. Since no ex-situ recycling was involved in these strategies no score was reported. It is important to mention that the assigned target levels for these parameters and the corresponding sustainability rewards points can be adjusted to reflect the local conditions and policies pertinent to the construction project. For example, in some regions recycling practice may be more widespread, thus higher levels of recycling use may be required to reward higher scores. On the other hand, if water conservation or energy reduction is more critical, a small amount of reduction of these parameters may be rewarded with higher score points. The scoring results of each alternative rehabilitation strategy can be then represented by an Amoeba chart, Figure 11. This chart provides a quantitative and visual review of the 
awarded points for each parameter relative to the maximum values. This representation visually indicates in which areas a rehabilitation strategy has provided the maximum score, and thus identifies the remaining areas that further improvement is needed. The Amoeba for alternative strategy $1-5$ is shown in Figure 11.

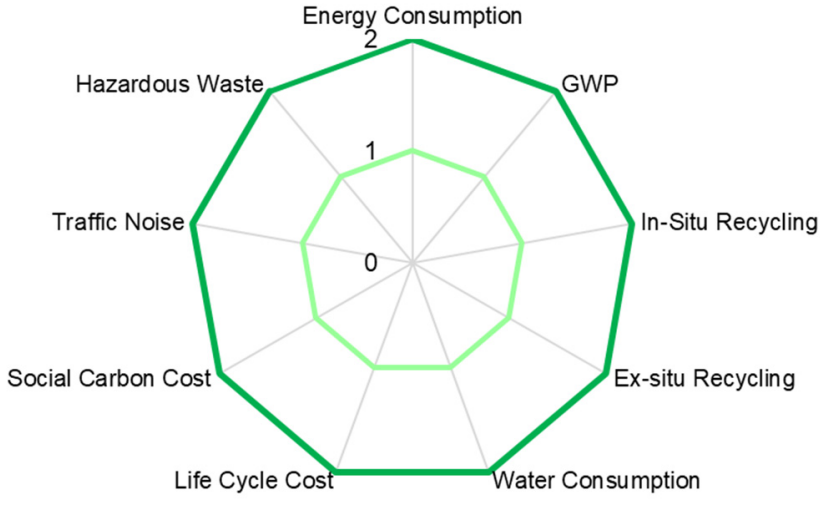

Figure 10. Components of $\mathrm{BE}^{2} \mathrm{ST}$-in-Highways rating system.

Table 4. Example sustainability assessment and scoring.

\begin{tabular}{ccccc}
\hline Criteria & $\begin{array}{c}\text { Reference } \\
\text { (Conventional) }\end{array}$ & $\begin{array}{c}\text { Alternative Strategy } \\
\mathbf{1 - 5}\end{array}$ & Performance & Normalized Score \\
\hline Energy Use (MJ) & $10,342,136$ & $8,229,633$ & $20.43 \%$ & 2 \\
GWP (Mg) & 573 & 447 & $21.99 \%$ & 2 \\
In-Situ Recycling (\%) & 0 & 1 & $100.00 \%$ & 2 \\
Ex-Situ Recycling (\%) & 0 & - & - & - \\
Water Consumption (kg) & 2290 & 2009 & $12.27 \%$ & 2 \\
Life Cycle Cost (USD) & $2,552,620$ & $1,952,232$ & 2 \\
Social Carbon Cost (USD) & USD 27,446.65 & USD 21,411.26 & USD 6.035 & 0.15 \\
Traffic Noise & - & 1 & 1 & 1 \\
Hazardous Waste (kg) & 78,161 & 75,597 & $3.28 \%$ & 0.33 \\
\hline
\end{tabular}

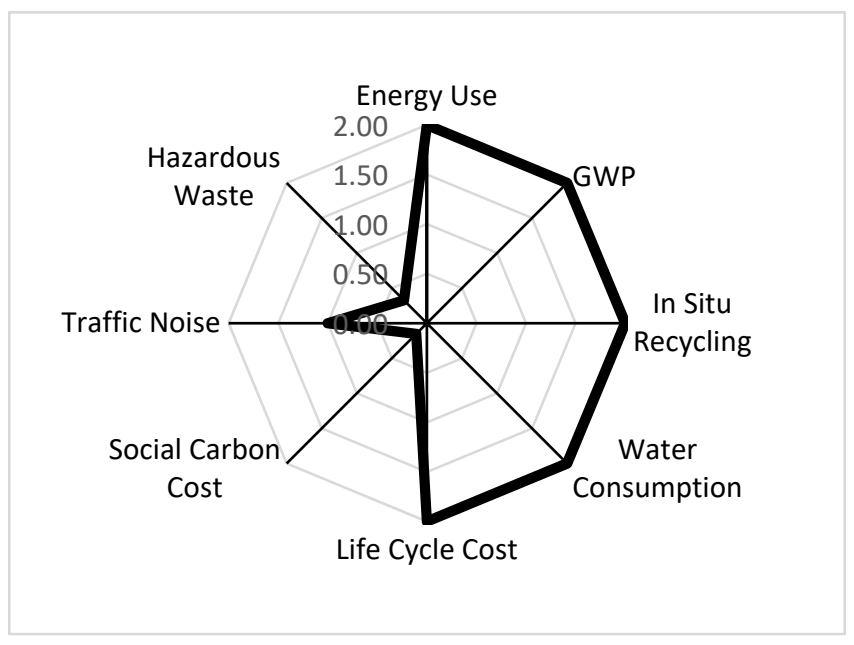

Figure 11. Sustainability scoring for alternative strategy 1-5. 


\section{Conclusions}

This paper presents a methodology for assessing alternative sustainable rehabilitation strategies for roadway construction. Such an approach could be integrated into a PMS for incorporating sustainability principles in optimizing alternative rehabilitation strategies. The methodology includes various steps for identifying and analyzing alternative sustainable strategies. The sustainability analysis considers both LCA economic and environmental effects of using recycled materials in pavement structures. It also provides significant insights on the contribution of materials production, transportation, and processing to such components. Two real case studies of typical rehabilitation construction projects were used to demonstrate the value of the sustainability assessment approach and showcasing the potential economic savings and environmental benefits of using recycled materials. The economic analysis indicated that using recycled materials on the surface, intermediate, and base layers in pavements can result in significant economic benefits. The environmental assessment for the alternative strategies indicated as well that overall higher percentages of recycled materials produce larger reductions in GHG emissions, energy, and water. While the specific findings of this study in relation to economic and environmental results reflect the construction project characteristics of the two case studies, it is expected that such trends will be similar to pavement projects in other regions where similar materials and construction techniques are used.

Author Contributions: Conceptualization, Y.Z., D.G., and D.P.; Formal analysis, Y.Z., D.G. and D.P.; Investigation, D.G. and D.P.; Methodology, Y.Z., D.G. and D.P.; Software, Y.Z. and D.P.; Supervision, D.G.; Visualization, Y.Z.; Writing-original draft, Y.Z., D.G. and D.P.; Writing-review and editing, Y.Z. and D.G. All authors have read and agreed to the published version of the manuscript.

Funding: This research received no external funding.

Institutional Review Board Statement: Not applicable.

Informed Consent Statement: Not applicable.

Conflicts of Interest: The authors declared no potential conflict of interest with respect to the research, authorship, and/or publication of this article.

\section{References}

1. Lee, J.; Edil, T.B.; Benson, C.H.; Tinjum, J.M. Building Environmentally and Economically Sustainable Transportation Infrastructure: Green Highway. J. Constr. Eng. Manag. 2013, 139. [CrossRef]

2. Lee, J.C.; Edil, T.B.; Tinjum, J.M.; Benson, C.H. Quantitative Assessment of Environmental and Economic Benefits of Recycled Materials in Highway Construction. Transp. Res. Rec. 2010, 2158, 138-142. [CrossRef]

3. National Academies of Sciences, Engineering, and Medicine. Recycling and Reclamation of Asphalt Pavements Using In-Place Methods; The National Academies Press: Washington, DC, USA, 2011. [CrossRef]

4. Chesner, W.; Collins, R.; MacKay, M. User Guidelines for Waste and By-Product Materials in Pavement Construction; FHWA-RD-97-148; Federal Highway Administration: McLean, VA, USA, 1998.

5. Horvath, A. A Life-Cycle Analysis Model and Decision-Support Tool for Selecting Recycled Versus Virgin Materials for Highway Applications; RMRC Research Project No 23; Federal Highway Administration: Washington, DC, USA, 2004.

6. Ventura, A.; Monéron, P.; Jullien, A. Environmental Impact of a Binding Course Pavement Section, with Asphalt Recycled at Varying Rates. Road Mater. Pavement Des. 2008, 9, 319-338. [CrossRef]

7. Al-Qadi, I.L.; Elseifi, M.; Carpenter, S.H. Reclaimed Asphalt Pavement-A Literature Review; FHWA-ICT-07-001; Illinois Department of Transportation: Springfield, IL, USA, 2007.

8. Aurangzeb, Q.; Al-Qadi, I.L.; Ozer, H.; Yang, R. Hybrid Life Cycle Assessment for Asphalt Mixtures with High RAP Content. Resources, Conservation and Recycling; Elsevier: Philadelphia, PA, USA, 2014; Volume 83.

9. Del Ponte, K.; Madras Natarajan, B.; Pakes Ahlman, A.; Baker, A.; Elliott, E.; Edil, T.B. Life-Cycle Benefits of Recycled Material in Highway Construction. Transp. Res. Rec. 2017, 2628, 1-11. [CrossRef]

10. Goulias, D.D.; Zhang, Y.; Aydilek, A. Sustainability Assessment of Roadways through Economic and Environmental Impact Life Cycle Analysis. Int. J. Comput. Eng. Res. 2018, 8, 1-8.

11. Pavement Life-Cycle Assessment Tool for Environmental and Economic Effects Version 2.0. Consortium on Green Design and Manufacturing, University of California, Berkeley. Available online: https://rmrc.wisc.edu/palate/ (accessed on 14 May 2021).

12. ASTM D6433-20. Standard Practice for Roads and Parking Lots Pavement Condition Index Surveys; ASTM International: West Conshohocken, PA, USA, 2020. 
13. Solla, M.; Pérez-Gracia, V.; Fontul, S. A Review of GPR Application on Transport Infrastructures: Troubleshooting and Best Practices. Remote Sens. 2021, 13, 672. [CrossRef]

14. Goulias, D.G.; Cafiso, S.; di Graziano, A.; Saremi, S.G.; Currao, V. Condition Assessment of Bridge Decks through GroundPenetrating Radar in Bridge Management Systems. J. Perform. Constr. Facil. 2020, 34, 1-13. [CrossRef]

15. Scott, M.; Goulias, D. Effective use of GPR Data in PMS for Identification of Homogeneous Sections with Uniform Pavement Thickness \& Assessing Thickness Variability: A Multi-Scale Approach. In Proceedings of the 9th International Conference on Managing Pavement Assets (ICMPA9), Washington, DC, USA, 18-21 May 2015.

16. Gomes, A.; Winter, M.G.; Puppala, A.J. A Review of Sustainable Approaches in Transport Infrastructure Geotechnics. Transp. Geotech. 2016, 7, 21-28. [CrossRef]

17. Reyes, O.; Berardinelli, E.; Alvarez, A.; Carvajal, J.; Fuentes, L. Evaluation of Hot Mix Asphalt Mixtures with Replacement of Aggregates by Reclaimed Asphalt Pavement (RAP) Material. Procedia-Soc. Behav. Sci. 2012, 53, 379-388. [CrossRef]

18. Vislavičius, K.; Sivilevičius, H. Effect of reclaimed asphalt pavement gradation variation on the homogeneity of recycled hot-mix asphalt. Arch. Civ. Mech. Eng. 2013, 13, 345-353. [CrossRef]

19. Association of State Highway and Transportation Officials (AASHTO). Guide for Design of Pavement Structures; AASHTO: Washington, DC, USA, 1993.

20. National Cooperative Highway Research Program (NCHRP). Guide for Mechanistic-Empirical Design of New and Rehabilitated Pavement Structures; NCHRP, Transportation Research Board, National Research Council: Washington, DC, USA, 2004.

21. Copeland, A. Reclaimed Asphalt Pavement in Asphalt Mixtures: State of the Practice; Publication FHWA-HRT-11-021; Turner-Fairbank Highway Research Center, Federal Highway Administration: McLean, VA, USA, 2011.

22. Baladi, G.Y.; Dawson, T.; Musunuru, G.; Prohaska, M.; Thomas, K. Pavement Performance Measures and Forecasting and the Effects of Maintenance and Rehabilitation Strategy on Treatment Effectiveness; Report No. FHWA-HRT-17-095; United States Federal Highway Administration: Washington, DC, USA, 2017.

23. Cafiso, S.; Di Graziano, A.; Goulias, D.; D’Agostino, C. Distress and Profile Data Analysis for Condition Assessment in Pavement Management Systems. Int. J. Pavement Res. Technol. 2019, 12, 527-536. [CrossRef]

24. Schwartz, C.W.; Andrews, J.; Stephanos, P.; Goulias, D. Laboratory Evaluation of Inertial Profiler Accuracy. In Proceedings of the 2002 Pavement Evaluation, TRB, National Academies, Roanoke, VA, USA, 21-25 October 2002.

25. Life-Cycle Cost Analysis in Pavement Design. Pavement Division Interim Technical Bulletin FHWA-SA-98-079, FHWA; U.S. Department of Transportation: Washington, DC, USA, 1998.

26. Recycled Materials Resource Centre. RMRC. Building Environmentally and Economically Sustainable Transportation-InfrastructureHighways. BE2ST-in-Highways User's Manual; University of Wisconsin-Madison: Madison, WI, USA, 2012.

27. Filho, W.U.; Klinsky, L.M.G.; Motta, R.; Bernucci, L.L.B. Cold Recycled Asphalt Mixture using 100\% RAP with Emulsified Asphalt-Recycling Agent as a New Pavement Base Course. Adv. Mater. Sci. Eng. 2020, 2020, 5863458. [CrossRef] 